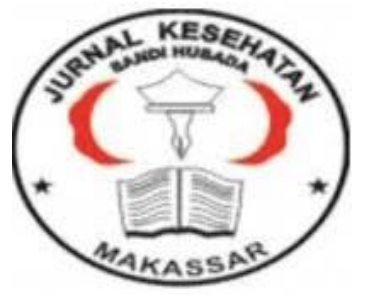

\author{
Jurnal Ilmiah Kesehatan Sandi Husada \\ hhttps://akper-sandikarsa.e-journal.id/JIKSH \\ Volume 9, Nomor 2, Desember 2020, pp 609-614 \\ p-ISSN: 2354-6093 dan e-ISSN: 2654-4563 \\ DOI: $10.35816 /$ jiskh.v10i2.363
}

\title{
Pengetahuan Pasien Tentang Penyakit TB Paru Di Balai Besar Kesehatan Paru Masyarakat Makassar
}

Knowledge Patient about Pulmonary Tuberculosis at Makassar Public Lung Health Center

\author{
Nurhaedah' ${ }^{1}$, Herman Herman ${ }^{2}$ \\ ${ }^{1}$ Akademi Keperawatan Yapenas 21 Maros \\ 2Jurusan Farmasi Politeknik Sandi Karsa
}

\section{Artikel info}

Artikel history:

Received; Juni 2020

Revised: Juli 2020

Accepted;Juli 2020
Abstrak. Latar belakang: TB paru merupakan penyakit yang sederhana serta mudah diobati dan pengelolaan utamanya adalah mengobati gejalanya saja. Pengetahuan yang terbatas tentang TB paru ini membuat penyakit ini sering kali tidak tertangani dengan baik. Metode: Jenis penelitian analitik deskriptif, dimana metode yang digunakan dalam pengumpulan data dengan penyebaran kuisioner kepada responden. Populasi dalam penelitian ini adalah semua pasien yang datang berobat. Pengolahan data penelitian dilakukan dengan melalui tahap-tahap sebagai berikut: seleksi, editing, koding, tabulasi. Analisis data yang digunakan pada penelitian ini adalah analisis deskriptif. Hasil: menunjukan berpengetahuan baik tentang cara penularan, keteraturan minum obat dan komplikasi penyakit TB Paru sebanyak 10 orang (33\%) dan yang berpengetahuan kurang tentang cara penularan, keteraturan minum obat dan komplikasi penyakit TB Paru sebanyak 20 orang (67\%).Kesimpulan: Sebagian besar memiliki berpengetahuan kurang tentang cara penularan, keteraturan minum obat dan komplikasi penyakit TB Paru. Hal ini menunjukkan bahwa pengetahuan yang dimiliki oleh pasien TB Paru belum begitu luas tentang komplikas penyakit TB Paru. Memberikan motivasi dan dorongan yang membangun pada pasien TB Paru serta memberikan penyuluhan kesehatan secara efektif pada pasien TB Paru saat berobat.

Abstract. Background: Pulmonary TB is a simple disease that is easy to treat and its main management is to treat the symptoms only. Limited knowledge about pulmonary TB makes this disease often not handled properly. Method: This type of descriptive analytic research, where the method used in data collection by distributing questionnaires to respondents. The population in this study were all patients who came for treatment. Research data processing is carried 
out through the following stages: selection, editing, coding, tabulation. Analysis of the data used in this research is descriptive analysis. Results: showed good knowledge about the way of transmission, regularity of taking medication and complications of pulmonary TB as many as 10 people (33\%) and those who lack knowledge about the mode of transmission, regularity of taking drugs and complications of pulmonary TB as many as 20 people (67\%). Most of them have less knowledge about the mode of transmission, regular medication and complications of pulmonary TB disease. This shows that the knowledge possessed by patients with pulmonary TB is not so broad about the complications of pulmonary TB disease. Providing constructive motivation and encouragement to pulmonary $T B$ patients and providing effective health education to pulmonary $T B$ patients when seeking treatment.

Keywords:

Knowledge;

Regularity of treatment:

Mode of transmission;
Coresponden author:

Email: nurhaedah.iskandar@gmail.com

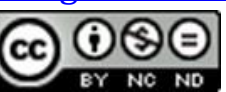

artikel dengan akses terbuka dibawah lisensi BCC BY NC ND-4.0

\section{Pendahuluan}

Setiap tahun tuberculosis membunuh hampir 2 juta orang diseluruh dunia. WHO memprediksi angka ini akan semakin memburuk pada dekade mendatang. 100 juta kasus TB paru diperkirakan bertambah pada tahun 2020 dan kurang lebih 36 juta orang di khawatirkan meninggal akibat penyakit ini. Malahan kini tiap detik satu orang di perkirakan terinfeksi TB. Tuberkulosis paru merupakan penyakit tata cara kehidupan penderita (Syaharuddin, 2010). Infeksi yang men yerang parenkim paru-paru yang disebabkan oleh mycrobacterium tuberculosis. Penyakit ini juga dapat menyerang ke bagian tubuh lain seperti meningen, ginjal, tulang dan nodus limfe (Somantri, 2008).

TB paru menjadi penyakit yang sangat di perhitungkan saat meningkatnya morbiditas penduduk terutama di Negara berkembang. Diperkirakan sepertiga populasi dunia terinfeksi mycrobacterium tuberculosis (Somantri, 2008). Hingga abad ke-20 penyakit TB paru masih merupakan masalah kesehatan dinegara berkembang dan mulai berkurang setelah diterapkan prinsip-prinsip pengobatan dengan perbaikan gizi dan Pada tahun 1995 hasil survei kesehatan rumah tangga menunjukkan bahwa penyakit TBC merupakan penyebab kematian nomor 3 setelah penyakit kardiovaskuler dan penyakit infeksi saluran pernapasan pada semua kelompok usia, dan nomor 1 dari golongan penyakit infeksi. Hal ini menunjukkan bahwa pengetahuan mengenai TB paru di masyarakat masih rendah walaupun TB paru merupakan penyakit yang sangat luas di masyarakat, namun penyakit ini kurang begitu dipahami, sehingga timbul anggapan dari masyarakat bahwa TB paru merupakan penyakit yang sederhana serta mudah diobati dan pengelolaan utamanya adalah mengobati gejalanya saja. Pengetahuan yang terbatas tentang TB paru ini membuat penyakit ini sering kali tidak tertangani dengan baik (Fairawan, 2009).

Tuberkulosis adalah penyakit yang disebabkan oleh Mycobacterium Tuberculosis. Bakteri ini menyerang paru-paru tetapi tidak menutup kemungkinan menyerang bagian tubuh lainnya. Penyakit ini dapat ditularkan melalui batuk yang mengandung Mycobacterium 
Tuberculosis dan menyebar ke udara. Indonesia adalah salah satu negara di dunia yang memiliki prevalensi tuberkulosis tinggi dan masih meningkat dalam jumlah kasus setiap tahun. Tingkat pendidikan adalah salah satu faktor yang mempengaruhi kejadian tuberkulosis. Semakin tinggi tingkat pendidikan seseorang, semakin rendah kejadian TBC. Ini karena seseorang yang memiliki tingkat pendidikan tinggi dapat memperoleh dan menyerap informasi lebih baik tentang TBC, sehingga mudah untuk mengambil tindakan pencegahan untuk menghindari TBC. Selain itu, semakin tinggi tingkat pendidikan seseorang akan secara tidak langsung mempengaruhi tingkat kesehatan (Muhammad, 2019). Gejala penyakit TB Paru dalam konsep dasar tidak jauh beda dengan tinjauan kasus namun ada beberapa gejala yang tidak muncul seperti tidak ada nafsu makan, keringat malam, sakit kepala, meriang, nyeri otot dan demam. Hal ini disebabkan karena keluhan tersebut umumnya muncul pada awal terjadinya penyakit. (Tri Maya Cahya Mulat, 2018). Tujuan penelitian diketahuinya Pengetahuan Pasien Tentang Penyakit TB Paru di Balai Besar Kesehatan Paru Masyarakat Makassar.

\section{Metode}

Jenis penelitian yang dilakukan adalah penelitian analitik deskriptif yaitu suatu penelitian yang digunakan untuk memperoleh gambaran pengetahuan pasien tentang penyakit TB paru, dimana metode yang digunakan dalam pengumpulan data dengan penyebaran kuisioner kepada responden. Penelitian ini dilakukan di Balai Besar Kesehatan Paru Masyarakat Makassar, dengan pertimbangan tempat ini merupakan satu-satunya tempat pengobatan khusus untuk penderita penyakit TB paru di Kota Makassar.

Populasi dalam penelitian ini adalah semua pasien yang datang berobat di Balai Besar Kesehatan Paru Masyarakat Makassar. Sampel dalam penelitian ini adalah pasien rawat jalan yang datang berobat di Balai Besar Kesehatan Paru Masyarakat Makassar . Tehnik pengambilan sampel yang digunakan adalah "non probability" jenis accidental sampling yaitu dilakukan dengan mengambilkan responden yang kebetulan ada atau tersedia. Pengolahan data penelitian dilakukan dengan melalui tahap-tahap sebagai berikut: seleksi, editing, koding, tabulasi. Analisis data yang digunakan pada penelitian ini adalah analisis deskriptif, untuk mengetahui distribusi frekuensi sesuai dengan variabel yang hendak diukur atau yang di amati.

\section{Hasil Dan Pembahasan}

Tabel 1. Distribusi Frekuensi Responden Menurut Karakteristik Responden Di Balai Besar Kesehatan Paru Masyarakat Makassar

\begin{tabular}{lcc}
\hline Karakteristik Responden & $\begin{array}{c}\text { Frekuensi } \\
\text { (f) }\end{array}$ & $\begin{array}{c}\text { Persentase } \\
\text { (\%) }\end{array}$ \\
\hline Jenis Kelamin & \multicolumn{2}{|c}{} \\
\hline Laki-laki & 17 & 56,7 \\
\hline Perempuan & 13 & 43,3 \\
\hline Umur & 4 & 13,3 \\
\hline$<25$ tahun & 22 & 73,4 \\
\hline $25-50$ tahun & 4 & 13,3 \\
$>50$ tahun & & \\
\hline Pendidikan & 11 & 36,7 \\
\hline SD & 5 & 16,7 \\
\hline SMP & 8 & 26,7 \\
\hline SMA & 4 & 13,3 \\
\hline DIPLOMA & &
\end{tabular}




\begin{tabular}{lcc}
\hline S1 & 2 & 6,6 \\
\hline Pekerjaan & & \\
\hline PNS & 2 & 7 \\
\hline NON PNS & 28 & 93 \\
\hline Jumlah & $\mathbf{3 0}$ & $\mathbf{1 0 0}$ \\
\hline
\end{tabular}

Sumber; Data primer

Tabel 2. Berdasarkan Pengetahuan Tentang Cara Penularan keteraturan minum obat dan komplikasi Penyakit TB Paru di Balai Besar Kesehatan Paru Masyarakat Makassar

Cara Penularan TB Paru $\quad$ Frekuensi (f) $\quad$ Presentase (\%)

\begin{tabular}{ccc} 
Baik & 10 & 33 \\
Kurang & 20 & 67 \\
& & \\
\hline Total & $\mathbf{3 0}$ & $\mathbf{1 0 0 , 0}$ \\
\hline
\end{tabular}

Sumber; Data primer

Berdasarkan hasil penelitian yang dilaksanakan Di Balai Besar Kesehatan Paru Masyarakat Makassar, maka data yang diperoleh di Balai Besar Kesehatan Paru Masyarakat Makassar, maka responden yang berpengetahuan baik tentang cara penularan, keteraturan minum obat dan komplikasi penyakit TB Paru sebanyak 10 orang (33\%) dan yang berpengetahuan kurang tentang cara penularan, keteraturan minum obat dan komplikasi penyakit TB Paru sebanyak 20 orang (67\%).

Menurut (Suprapto, 2018) bahwa pengetahuan masyarakat sebagian masih kurang terhadap upaya pencegahan tuberculosis akan tetapi dengan pengetahuan yang ada tidak mempengaruhi sikap masyarakat dalam upaya pencegahan. Berdasarkan hasil penelitian maka disarankan perlu ditingkatkan lagi penyuluhan yang lebih intensif dalam rangka menggerakkan masyarakat dalam upaya pencegahan Tuberculosis. Sikap responden tentang penyakit tuberculosis positif yaitu 32 responden dengan cara menghindar penderita tuberculosis, dan sikap negatif yaitu 18 responden karena responden tidak tau cara penangana atau menghindar penderita tuberculosis sikap responden terhadap upaya pencegahan tuberculosis sangat baik (Maria Kurni Mengea, 2017).

Menurut hasil (Dhewi, Armiyati, \& Supriyono, 2012) penelitian menunjukkan ada hubungan bermakna antara sikap dengan kepatuhan minum obat TB Paru dengan nilai $\mathrm{p}=0,001$. Ada hubungan yang bermakna antara dukungan keluarga dengan kepatuhan minum obat TB Paru dengan nilai $\mathrm{p}=0,000$. Rekomendasi yang dapat diberikan adalah agar BKPM Pati mengoptimalkan penyuluhan kesehatan agar pasien tetap patuh minum obat, dan keluarga diharapkan selalu memberikan dukungan dan motivasi pada pasien.

Ini disebabkan karena beberapa factor diantaranya adalah jenis kelamin, dimana pada seorang pria lebih sering merokok, mengkonsumsi alcohol, dan kebiasaan-kebiasaan lain yang tidak sesuai dengan gaya hidup sehat serta adanya perbedaan lingkungan kerja dimana laki-laki lebih banyak beraktivitas di luar rumah dibanding perempuan, kurangnya pengetahuan dan pendidikan yang rendah, serta budaya dimana seorang bapak yang terinfeksi kuman TB yang selalu kontak langsung dengan anak-anaknya. Untuk menghindari atau memutuskan rantai penularan penyakit TB tersebut maka harus menjalankan pola hidup sehat seperti gizi seimbang, berhenti merokok, lingkungan yang bersih, dan olah raga teratur agar kondisi tubuh lebih kuat terhadap paparan penyakit (Suarni, 2009).

Maka untuk membuka wawasan mereka tentang cara penularan TB Paru maka harus di 
lakukan penyuluhan kesehatan dari pusat pelayanan kesehatan agar pasien dapat mengetahui tentang konsep penyakit TB Paru dan dapat memutuskan rantai penularan penyakit tersebut, sehingga tidak ada anggapan lagi bahwa penyakit TB Paru ini merupakan penyakit keturunan dan mematikan. Keteraturan pengobatan pada penyakit TB Paru bertujuan untuk menyembuhkan pasien dari penyakitnya, selain itu harus diperhatikan juga frekuensi dan waktu untuk pengobatan dan jenis obat-obatan yang di minum. Hal ini disebabkan karena factor pendidikan dan pengetahuan yang minim dari pasien mengenai pengobatan penyakit TB Paru (Ruswanto, 2010)

Hasil penelitian ini sejalan dengan penelitian yang dilakukan oleh (Dewi, Zainal, \& Indar, 2013) bahwa 86\% Penderita TB paru selalu menggunakan obat-obatan antibiotik Non OAT untuk pengobatan penyakitnya dan selalu putus berobat akibat tidak aktifnya seorang PMO, kurangnya perhatian dari keluarga, dan kurangnya faktor ekonomi yang memadai untuk berobat ketempat pelayanan kesehatan. Komplikasi suatu penyakit diakibatkan karena kurangnya penanganan yang baik dan tepat pada penyakit tersebut. Jutaan manusia sebenarnya hidup dengan kuman tuberkolosis tanpa harus menjadi sakit. Penderita yang mengalami komplikasi berat perlu dirawat di rumah sakit. Beberapa komplikasi dari penyakit TB paru diantaranya adalah sesak nafas dan terjadinya penyebaran infeksi kuman TB ke organ lain.

Umumnya pasien TB Paru tidak mengetahui tentang beberapa masalah dari komplikasi penyakit TB Paru. Komplikasi dari TB Paru tersebut adalah sesak nafas dan penyebaran infeksi kuman TB ke organ lain (tulang dan otak), pneumotoraks dan bahkan bisa terjadi HIV/AIDS. Sehingga pada saat muncul salah satu dari beberapa komplikasi itu maka yang dipikirkan oleh pasien adalah itu merupakan penyakit baru yang bukan disebabkan oleh TB Paru, sehingga pengobatan yang digunakan adalah simptomatik atau untuk mengobati gejala yang muncul saja. Hasil penelitian ini sejalan dengan perkiraan menurut badan kesehatan dunia (WHO) bahwa sekitar sepertiga kematian pada penderita AIDS di Afrika disebabkan oleh Tuberkulosis dan sekitar $40 \%$ kematian pada penderita HIV/AIDS di sebabkan oleh penyakit TB Paru. (Syaharuddin, 2010). Hal ini menunjukkan bahwa pengetahuan yang dimiliki oleh pasien TB Paru belum begitu luas tentang komplikas penyakit TB Paru.

\section{Simpulan Dan Saran}

Sebagian besar memiliki berpengetahuan kurang tentang cara penularan, keteraturan minum obat dan komplikasi penyakit TB Paru. Hal ini menunjukkan bahwa pengetahuan yang dimiliki oleh pasien TB Paru belum begitu luas tentang komplikas penyakit TB Paru. Memberikan motivasi dan dorongan yang membangun pada pasien TB Paru serta memberikan penyuluhan kesehatan secara efektif pada pasien TB Paru saat berobat. Masyarakat perlu lebih meningkatkan penyuluhan kepada kelompok laki-laki (khususnya perokok) dan kelompok umur yang berisiko tinggi tentang cara penularan penyakit TB Paru, keteraturan pengobatan TB Paru dan komplikasi dari penyakit TB Paru tersebut sehingga menambah wawasan pengetahuan mereka tentang penyakit TB Paru.

\section{Daftar Rujukan}

Dewi, A. M., Zainal, S., \& Indar, I. (2013). Faktor-Faktor Yang Mempengaruhi Masyarakat Dalam Upaya Pencegahan Tuberkulosis Di Kelurahan Balakia Wilayah Kerja Puskesmas Manipi Sinjai Barat. Jurnal Ilmiah Kesehatan Diagnosis, 3(2), 106-114.

Dhewi, G. I., Armiyati, Y., \& Supriyono, M. (2012). Hubungan antara pengetahuan, sikap pasien dan dukungan keluarga dengan kepatuhan minum obat pada pasien TB 
paru di BKPM Pati. Karya Ilmiah.

Fairawan, S. (2009). Hubungan antara Pengetahuan Tentang Penyakit Asma dengan Sikap Penderita dalam Perawatan Asma pada Pasien Rawat Jalan di Balai Besar Kesehatan Paru Masyarakat (BBKPM) Surakarta. Universitas Muhammadiyah Surakarta.

Maria Kurni Mengea. (2017). Pengaruh Pengetahuan Dan Sikap Masyarakat Dalam Upaya Pencegahan Tb Di Wilayah Kelurahan Pallantikan Kabupaten Maros. Jurnal Ilmiah Kesehatan Sandi Husada, 6(2 SE-Articles). Retrieved from https://akpersandikarsa.e-journal.id/JIKSH/article/view/203

Muhammad, E. (2019). Hubungan Tingkat Pendidikan Terhadap Kejadian Tuberkulosis Paru. Jurnal Ilmiah Kesehatan Sandi Husada, 10(2 SE-Articles). Retrieved from https://akper-sandikarsa.e-journal.id/JIKSH/article/view/173

Ruswanto, B. (2010). Analisis spasial sebaran kasus tuberkulosis paru ditinjau dari faktor lingkungan dalam dan luar rumah di Kabupaten Pekalongan. UNIVERSITAS DIPONEGORO.

Somantri, I. (2008). Keperawatan medikal bedah: Asuhan keperawatan pada pasien dengan gangguan sistem pernapasan. Jakarta: Salemba Medika.

Suarni, H. (2009). Faktor Risiko yang Berhubungan dengan Kejadian Penderita TB Paru BTA Positif di Kecamatan Pancoran Mas Kota Depok Bulan Oktober Tahun 2008April Tahun 2009. Fakultas Kesehatan Masyarakat Universitas Indonesia, 22-23.

Suprapto, S. (2018). Pengetahuan Dan Sikap Masyarakat Dalam Upaya Pencegahan Tuberkulosis Di Wilayah Kerja Puskesmas Batua Kota Makassar. Jurnal Ilmiah Kesehatan Sandi Husada, 7(1 SE-Articles).

Retrieved from https://akper-sandikarsa.e-journal.id/JIKSH/article/view/10

Syaharuddin. (2010). Modul Pembelajaran Penanggulangan Penyakit Tuberkulosis Oleh Perawat. Makassar: PSIK-FK UNHAS.

Tri Maya Cahya Mulat. (2018). Studi Kasus Pada Keluarga Ny "H" Dengan Anggota Keluarga Yang Mengalami Gangguan Kesehatan Tb Paru Kelurahan Mangasa Kecamatan Tamalate Kota Makassar. Jurnal Ilmiah Kesehatan Sandi Husada, 7(1 SE-Articles).

Retrieved from https://akper-sandikarsa.e-journal.id/JIKSH/article/view/9 